\title{
Ensayo de adaptación de dos nuevos clones de papa con aptitud para procesamiento y consumo directo en condiciones de Cañete
}

\section{Adaptation trial of two new clones of potato for processing and direct consumption in Cañete}

\author{
Recibido: 23/07/2015 Revisado: 21/08/2015 Aceptado: 11/09/2015
}

Sergio Eduardo Contreras', Jorge Espinoza Trelles²

\section{RESUMEN}

Objetivo: Comparar la productividad y adaptación de dos nuevos clones de papa (Solanum tuberosum) para procesamiento y consumo directo. Métodos: Se utilizó el diseño experimental de bloques completos al azar con 3 repeticiones y 4 genotipos de papa (2 clones experimentales y 2 variedades comerciales como testigos), en la localidad de Imperial, provincia de Cañete, en un suelo franco arenoso y bajo condiciones de invierno del 2013. Se evaluaron 13 caracteres agronómicos y se usó la prueba de significancia de Tukey para comparar las medias de los genotipos, mediante el programa Infostat. Resultados. En cuanto a las variables producción de tubérculos, número de tubérculos, follaje y biomasa, tanto el clon Faustina como Yasmine presentaron niveles similares a la variedad comercial Perricholi, aunque algo menor a Única. El clon Faustina, tuvo $0 \%$ incidencia de síntomas de virosis, lo cual puede ser importante para la multiplicación vegetativa de este clon; el brotamiento de los genotipos evaluados tanto clones como variedades fue homogéneo. Conclusiones: Se puede afirmar de acuerdo a la información experimental, que los clones Faustina y Yasmine tienen características apropiadas para su producción comercial y presentan un potencial para ser consideradas como nuevos cultivares.

Palabras clave: Ensayo agronómico, diseño de bloques completos, papa, selección varietal.

\section{ABSTRACT \\ Objetive: To evaluate production and adaptation of two new clones of potato (Solanum tuberosum) for processing and direct consumption. Methods: Randomized Block Design with 3 replications was used and 4 genotypes (including 2 new potato clones and 2 commercial varieties as controls) at Imperial (Cañete) in winter conditions year 2013. 13 variables were evaluated and Tukey test was used to compare genotypes; Infostat software for processing data. Results: New potato clones Faustina and Yasmine had similar characteristics to commercial variety Perricholi for tuber production, tuber number, foliage weight and total biomass but less than Unica cultivar. Faustina clone had $0 \%$ for virus symptoms incidence, so it can have relevance to tuber multiplication; tuber sprout were uniform for clones and varieties. Conclusions: According to experimental data, Faustina and Yasmine clones have appropriate characteristics for commercial production and potential as new potato varieties.}

Keywords: Agronomical trial, randomized block design, potato, cultivar selection.

\section{INTRODUCCIÓN}

La papa es un producto nutritivo y una alternativa para la alimentación mundial por su valioso contenido de carbohidratos, proteínas, hierro, zinc y un contenido importante de vitamina $C$, potasio y calcio. El Perú posee la mayor diversidad de variedades de papa en el mundo siendo las zonas productoras: costa y sierra. Se están realizando estudios de nuevas variedades resistentes que puedan superar a las variedades tradicionales y por ende proporcionen un mayor ingreso económico para los agricultores. Hoy en día la producción de papa representa el $8 \%$ del Valor Bruto de la producción agrícola nacional, índice mayor que cualquier otro cultivo alimenticio nacional.

De acuerdo a información del Centro Internacional de la Papa (CIP, 2014) el clon CIP396311.1 se caracteriza por poseer una alta resistencia a PVY y PVX y moderada resistencia al PLVR (virus del enrollamiento), además de precocidad y tolerancia a condiciones de sequía; por su parte el clon CIP399101.1 presenta alta resistencia a PVY pero susceptibilidad a PVX y PLRV, además de tolerancia a condiciones de calor, presentando ambos clones buena aptitud para el procesamiento (buen contenido de materia seca aproximadamente $22 \%$ y bajo tenor de azúcares reductores).

De acuerdo a Maldonado, Suárez \& Thiele (2008) en las década de 1960-2000, la producción de papa en el Perú se ha incrementado de 1,3 a 3 millones de toneladas anuales. Este volumen de producción ha convertido al país en el mayor productor de papa en América Latina. EI CIP ha colaborado con una amplia variedad de material genético para el desarrollo y lanzamiento de nuevas variedades de papas con diferentes características; entre estas variedades los autores mencionan a la variedad CanchánINIAA liberada por el Instituto Nacional de Investigación Agraria en 1990, y que actualmente es la más cultivada a nivel nacional.

Por su parte Gutiérrez-Rosales, Espinoza-Trelles \& Bonierbale (2007) destacan que la Universidad Nacional San Luis Gonzaga realizó la inscripción de la variedad Única en el Registro Nacional de Variedades Comerciales del Servicio Nacional de Sanidad Agraria. Entre sus principales atributos resaltan la resistencia a virus (PVY), tolerancia al calor, moderada resistencia al nematodo del nudo (Meloidogyne sp.), precocidad, estabilidad de rendimiento en varias épocas de siembra y leve tolerancia a sales.

La variedad Perricholi tiene una excelente capacidad de producción y adaptación pero bajo contenido 
de materia seca en los tubérculos con fuerte tendencia a ser muy grandes, así como resistencia a la rancha, de acuerdo a información de Egúsquiza y Catalán (2011).

El objetivo de la presente investigación fue comparar la productividad y adaptación de dos nuevos clones de papa para procesamiento y consumo directo en relación a dos cultivares comerciales, con fines de registro ante la autoridad nacional de semillas.

\section{MATERIALES Y MÉTODOS}

\section{Localidad}

Anexo San Isidro, Distrito de Imperial, Provincia de Cañete, Departamento de Lima.

\section{Condiciones de suelo y clima}

Se realizó el análisis de suelos y los resultados mostraron un tipo de suelo franco arenoso, $\mathrm{pH} 7,8$, libres de sales y bajo contenido de materia orgánica. Las temperaturas fueron: Máxima $24^{\circ} \mathrm{C}$ y mínima $16^{\circ} \mathrm{C}$ durante el ciclo vegetativo del cultivo, tomados de los registros de la Asociación de Productores de Cañete.

\section{Material experimental}

Se utilizaron las variedades comerciales: Canchan INIAA y Perricholi, como testigos y los clones experimentales C95.256 (CIP396311.1) denominado Faustina y C99.551 (CIP399101.1) denominado Yasmine, provistos por el Centro Internacional de la Papa (CIP). Este material genético avanzado había sido evaluado previamente en un trabajo de investigación en la Universidad Nacional José Faustino Sánchez Carrión.

\section{Procedimientos}

Se estableció el área experimental en un terreno de cultivo de la localidad señalada, para lo cual se diseñó el campo de acuerdo al croquis experimental, considerando los bloques y los tratamientos al azar dentro de cada uno de ellos. El manejo agronómico fue el que normalmente se utiliza en campos de cultivo comercial de manera que se simulen las condiciones de manejo agronómico; se aplicó una dosis de fertilización de 150-0-0. Con excepción de los tratamientos en estudio, todas la demás labores (preparación de terreno, siembra, deshierbo, riegos y distanciamientos) fueron uniformes en el área experimental.

\section{Variables evaluadas}

Se evaluaron las siguientes características agronómicas: densidad de tallos a los 15 días, número de brotes/planta a los 30 días, vigor vegetativo, altura de planta, \% Floración, \% Sobrevivencia a la cosecha, vigor vegetativo, incidencia de virosis (\%), peso de follaje, número de tubérculos, peso de tubérculos/planta, rendimiento total/ha y peso total de la Biomasa/ha ( $\mathrm{t}$ ).

\section{Diseño experimental}

Se utilizó el diseño experimental de bloques completos al azar (DBCA), con 3 repeticiones de cada genotipo de papa. El tamaño de la unidad experimental fue de 60 plantas $\left(18 \mathrm{~m}^{2}\right)$.

\section{Procesamiento de datos}

Se usó la técnica de análisis de la variancia y la prueba de significancia de Tukey para comparar las medias de tratamiento. El programa Infostat versión junio 2015, se utilizó para procesar la información

\section{RESULTADOS}

El análisis de variancia para los caracteres evaluados se presenta en las tablas 1 y 2 . Se aprecia que existió variabilidad significativa entre los genotipos evaluados para los caracteres: Densidad de tallos, altura de planta, floración, sobrevivencia a la cosecha, incidencia de virus, peso de follaje por planta, número de tubérculos por planta, rendimiento total/ha y peso total de la biomasa/ha. Por su parte, en cuanto al número de brotes por planta, vigor vegetativo y peso de tubérculos por planta, no se encontraron diferencias entre los genotipos.

El coeficiente de variabilidad tuvo una magnitud menor a $20 \%$ en todos los caracteres y el ajuste del modelo estadístico medido como el coeficiente de determinación $\left(R^{2}\right)$, fue adecuado para dichas variables.

Tabla 1. Análisis de variancia para caracteres agronómicos en 4 genotipos de papa en Cañete.

\begin{tabular}{|c|c|c|c|c|c|c|c|c|}
\hline \multirow[b]{2}{*}{ Fuentes } & \multirow[b]{2}{*}{ Glibertad } & \multicolumn{5}{|c|}{ Cuadrados medios } & \multirow[b]{2}{*}{ Ivirus } & \multirow[b]{2}{*}{ \%Sobrev } \\
\hline & & Dtallos15d & NBrotes/pl & Aplant & Vigor & \%Florac & & \\
\hline Bloqueos & 2 & 3,2425 & 0,27 & 5,10 & 0,1158 & 1,7733 & 0,24 & 19,39 \\
\hline Genotipos & 3 & 1171,3497 & 0,29 & 464,18 & 0,4311 & 1264,91 & 66,23 & 326,47 \\
\hline Error & 6 & 175,2747 & 0,23 & 3,83 & 0,1636 & 0,7067 & 0,67 & 12,21 \\
\hline Total & 11 & & & & & & & \\
\hline Promedio & & 76,4 & 2,5 & 41,6 & 6,9 & 12,8 & 4,3 & 90,5 \\
\hline Coef. Variación \% & & 17,32 & 19,57 & 4,71 & 5,83 & 6,56 & 18,97 & 3,86 \\
\hline $\mathrm{R}^{2}$ & & 0,77 & 0,51 & 0,98 & 0,61 & 1,00 & 0,98 & 0,93 \\
\hline
\end{tabular}

+ Valores en negrita son estadísticamente significativos $(p<0,05)$ 
Tabla 2. Análisis de Variancia para caracteres productivos en 4 genotipos de papa en Cañete

\begin{tabular}{|c|c|c|c|c|c|c|c|}
\hline \multirow[b]{2}{*}{ Fuentes } & \multirow[b]{2}{*}{ Glibertad } & \multicolumn{5}{|c|}{ Cuadrados medios } & \multirow[b]{2}{*}{ Biomasa/ha } \\
\hline & & PFollaje/pl & PTuberc/pl & NTuberc/pl & PFollaje/ha & Rend/ha & \\
\hline Bloqueos & 2 & 0,0058 & 0,0008 & 0,6358 & 6,7608 & 5,2075 & 20,07 \\
\hline Genotipos & 3 & 0,0097 & 0,0289 & 4,3097 & 16,1853 & 63,7519 & 114,09 \\
\hline Error & 6 & 0,0014 & 0,0064 & 0,8014 & 1,2519 & 4,3953 & 9,26 \\
\hline Total & 11 & & & & & & \\
\hline Promedio & & 0,3 & 0,4 & 4,8 & 10,6 & 15,7 & 26,3 \\
\hline Coef. Variación \% & & 12,78 & 18,45 & 18,68 & 10,55 & 13,33 & 11,56 \\
\hline $\mathrm{R}^{2}$ & & 0,83 & 0,70 & 0,75 & 0,89 & 0,88 & 0,86 \\
\hline
\end{tabular}

+ Valores en negrita son estadísticamente significativos $(p<0,05)$

1. Densidad de tallos por parcela 15 días de la siembra En el caso de densidad de tallos/parcela a los 15 días de la siembra, no existieron diferencias significativas entre los genotipos Única, Perricholi y Faustina; por su parte, el clon Yasmine tuvo una menor densidad de tallos por unidad de área que el cultivar comercial Única.

Tabla 3. Densidad de tallos/parcela en 4 genotipos de papa en Cañete.

\begin{tabular}{lcll}
\hline Genotipos & Media & & \\
\hline Única & 99,30 & a & \\
Perricholi & 85,73 & a & b \\
Faustina & 65,00 & a & b \\
Yasmine & 55,67 & & b \\
Error estándar & 7,64 & & \\
\hline
\end{tabular}

+Medias con la misma letra no difieren estadísticamente

\section{Número de brotes por planta}

En relación a número de brotes por planta, no se encontraron evidencias de diferencias significativas entre los genotipos (tabla 4).

Tabla 4. Número de brotes/planta en 4 genotipos de papa en Cañete.

\begin{tabular}{lll}
\hline Genotipos & Media & \\
\hline Única & 2,87 & a \\
Perricholi & 2,50 & a \\
Faustina & 2,27 & a \\
Yasmine & 2,17 & a \\
Error estándar & 0,28 & \\
\hline
\end{tabular}

+Medias con la misma letra no difieren estadísticamente

\section{Altura de planta}

Con respecto a altura de planta $(\mathrm{cm})$, la variedad Perricholi presentó el mayor tamaño promedio por planta seguido de Única y Yasmine, mientras que Faustina tuvo el menor tamaño de planta.
Tabla 5. Altura de planta en 4 genotipos de papa en Cañete.

\begin{tabular}{lcccc}
\hline Genotipos & Media & & & \\
\hline Única & 59,33 & a & & \\
Perricholi & 40,17 & & b & \\
Faustina & 35,97 & & b & c \\
Yasmine & 30,83 & & & c \\
Error estándar & 1,13 & & & \\
\hline
\end{tabular}

+Medias con la misma letra no difieren estadísticamente

\section{Floración}

En cuanto a porcentaje de floración, la variedad Perricholi tuvo el más alto porcentaje seguido de Yasmine, mientras que Única y Faustina no presentaron floración.

Tabla 6. \% Floración en 4 genotipos de papa en Cañete.

\begin{tabular}{lrllll}
\hline Genotipos & Media & & & \\
\hline Única & 43,07 & a & & \\
Perricholi & 8,20 & & b & \\
Faustina & 0,00 & & & c \\
Yasmine & 0,00 & & & c \\
Error estándar & 0,49 & & & \\
\hline
\end{tabular}

+Medias con la misma letra no difieren estadísticamente

\section{Sobrevivencia a la cosecha}

En la tabla 7 se puede apreciar que la variedad Única y Faustina presentaron la mayor sobrevivencia a la cosecha seguido de Perricholi, y Yasmine tuvo menor sobrevivencia que el resto de genotipos.

Tabla 7. \% Sobrevivencia a la cosecha en 4 genotipos de papa en Cañete.

\begin{tabular}{lccccc}
\hline Genotipos & Media & & & \\
\hline Única & 99,27 & a & & \\
Perricholi & 97,37 & a & b & \\
Faustina & 89,17 & & b & \\
Yasmine & 76,33 & & & c \\
Error estándar & 2,02 & & & \\
\hline
\end{tabular}

+Medias con la misma letra no difieren estadísticamente 
6. Peso de follaje, $t / h a$.

En cuanto a peso de follaje por hectárea, se puede advertir en la tabla 8 que Faustina, Única y Perricholi tuvieron mayor peso de follaje que Yasmine.

Tabla 8. Peso de follaje (t/ha) en 4 genotipos de papa en Cañete.

\begin{tabular}{lccc}
\hline Genotipos & Media & & \\
\hline Única & 12,70 & a & \\
Perricholi & 11,47 & a & \\
Faustina & 10,97 & a & \\
Yasmine & 7,30 & & b \\
Error estándar & 0,65 & & \\
\hline
\end{tabular}

+Medias con la misma letra no difieren estadísticamente

\section{Número de tubérculos/planta}

Para número de tubérculos promedio por planta, tanto los cultivares Única y Perricholi como el clon Yasmine tuvieron similar valor para este carácter, mientras que Faustina tuvo el menor número de tubérculos.

Tabla 9. Número de tubérculos/planta en 4 genotipos de papa en Cañete.

\begin{tabular}{llll}
\hline Genotipos & Media & & \\
\hline Única & 6,23 & a & \\
Perricholi & 5,10 & a & b \\
Faustina & 4,47 & a & b \\
Yasmine & 3,37 & & b \\
Error estándar & 0,52 & & \\
\hline
\end{tabular}

+Medias con la misma letra no difieren estadísticamente

\section{Vigor vegetativo}

En relación a vigor vegetativo (escala fenotípica), no se encontraron evidencias de diferencias significativas entre los genotipos, presentando todos el mismo nivel de vigor (tabla 10).

Tabla 10. Vigor vegetativo en 4 genotipos de papa en Cañete.

\begin{tabular}{lll}
\hline Genotipos & Media & \\
\hline Única & 7,17 & a \\
Perricholi & 7,10 & a \\
Faustina & 7,10 & a \\
Yasmine & 6,37 & a \\
Error estándar & 0,23 & \\
\hline
\end{tabular}

+Medias con la misma letra no difieren estadísticamente

\section{Incidencia de Virus}

La incidencia por virus en las plantas fue alta en Perricholi, intermedia en Yasmine y muy baja en Única y Faustina, tal como se observa en la tabla 11.
Tabla 11. Incidencia de Virus (\%) en 4 genotipos de papa en Cañete.

\begin{tabular}{lcccc}
\hline Genotipos & Media & & & \\
\hline Única & 9,60 & a & & \\
Perricholi & 6,93 & & b & \\
Faustina & 0,73 & & & $c$ \\
Yasmine & 0,00 & & & c \\
Error estándar & 0,47 & & & \\
\hline
\end{tabular}

+Medias con la misma letra no difieren estadísticamente

\section{Peso promedio de tubérculos por planta}

En relación al carácter peso promedio de tubérculos por planta, se puede observar en la tabla 12 que el mayor valor se obtuvo para el cultivar Única, aunque no diferente estadísticamente de Perricholi y Yasmine mientras que el menor valor fue para el clon Faustina.

Tabla 12. Peso de tubérculos (k/planta) en 4 genotipos de papa en Cañete.

\begin{tabular}{llll}
\hline Genotipos & Media & & \\
\hline Única & 0,57 & a & \\
Perricholi & 0,43 & a & b \\
Faustina & 0,40 & a & b \\
Yasmine & 0,33 & & b \\
Error estándar & 0,05 & & \\
\hline
\end{tabular}

+Medias con la misma letra no difieren estadísticamente

\section{Rendimiento de tubérculos por hectárea}

Para rendimiento promedio de tubérculos por hectárea se observa en la tabla 13 que el cultivar Única presentó la más alta productividad, mientras que los demás genotipos no difirieron estadísticamente.

Tabla 13. Rendimiento de tubérculos/ha (t) en 4 genotipos de papa en Cañete.

\begin{tabular}{lccc}
\hline Genotipos & Media & & \\
\hline Única & 22,27 & a & \\
Perricholi & 15,53 & & $\mathrm{~b}$ \\
Faustina & 13,17 & $\mathrm{~b}$ \\
Yasmine & 11,93 & $\mathrm{~b}$ \\
Error estándar & 1,21 & & \\
\hline
\end{tabular}

+Medias con la misma letra no difieren estadísticamente

\section{Peso total de la biomasa/ha (t).}

Con respecto al peso de la biomasa total por hectárea, el cultivar Única obtuvo el más alto peso de biomasa, mientras que Yasmine tuvo el valor más bajo para este carácter.

Tabla 14. Peso total de la biomasa/ha (t) en 4 genotipos de papa en Cañete.

\begin{tabular}{lllll}
\hline Genotipos & Media & & & \\
\hline Única & 33,73 & a & & \\
Perricholi & 28,23 & a & b & \\
Faustina & 24,13 & & b & c \\
Yasmine & 19,20 & & & c \\
Error estándar & & & & \\
\hline
\end{tabular}

+Medias con la misma letra no difieren estadísticamente 


\section{Big Bang Faustiniano}

\section{Vicerrectorado de Investigación}

\section{DISCUSIÓN}

Los resultados presentado en la investigación coinciden con la información (CIP, 2014) de los genotipos experimentales evaluados en este ensayo en cuanto corresponde a resistencia a virus, periodo vegetativo, floración, entre otros caracteres. En cuanto a las variables relacionadas a producción como producción de tubérculos, número de tubérculos, follaje y biomasa, tanto el clon Faustina como Yasmine presentaron niveles similares a la variedad comercial Perricholi, aunque algo menor a Única. El clon Faustina, tuvo 0\% incidencia de síntomas de virosis, lo cual puede ser importante para la multiplicación vegetativa de este clon; el brotamiento de los genotipos evaluados tanto clones como variedades, fue homogéneo para la condiciones del ensayo lo cual se puede considerar como un criterio de la adaptación de este material genético.

Finalmente, se puede afirmar de acuerdo a la información experimental, que los clones Faustina y Yasmine tienen características apropiadas para su producción comercial y presentan un potencial para ser consideradas como nuevos cultivares en posteriores ensayos, previa validación en condiciones de campo de los resultados presentados en la investigación.

\section{Agradecimiento}

Se agradece al Centro Internacional de la Papa en especial a Rosario Falcón, de la Unidad de Adquisición y
Distribución de Germoplasma, por la provisión de las plantas in vitro de los clones experimentales, así como al Bachiller en Agronomía de la Universidad Nacional José Faustino Sánchez Carrión, Diego Huamán Tasa por el apoyo en el manejo del campo experimental y las evaluaciones.

\section{REFERENCIAS BIBLIOGRÁFICAS}

CIP (2014). Catalogue of potato varieties and advance clones 2014. Lima Peru.

Egusquiza, R., Catalan, W. (2011). Guía técnica. Curso Taller Manejo integrado de papa. UNALM-Agrobanco. Cuzco.

Maldonado, L; Suárez, V.; G. Thiele. (2008). Estudio de la adopción de variedades de papa en zonas pobres del Perú. Centro Internacional de la Papa (CIP). LimaPerú. Documento de Trabajo 2008-2. 37 p.

Gutiérrez-Rosales R, Espinoza-Trelles J, Bonierbale M. (2007). UNICA: variedad Peruana para mercado fresco y papa frita con tolerancia y resistencia para condiciones climáticas adversas. Revista Latinoamericana de la Papa. (2007). 14(1): 41-50

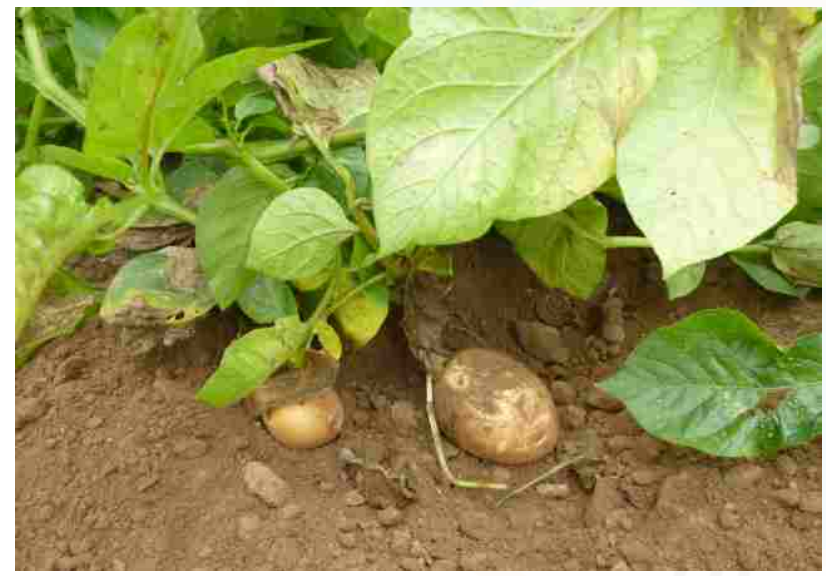

Figura 1. Tuberizacion en cv. Yasmine.

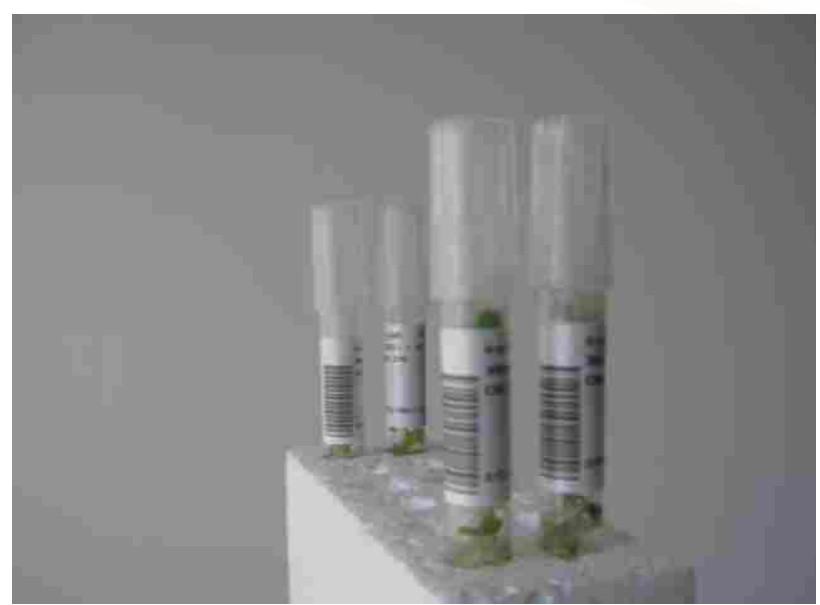

Figura 3. Plántulas in vitro de 2 clones de papa

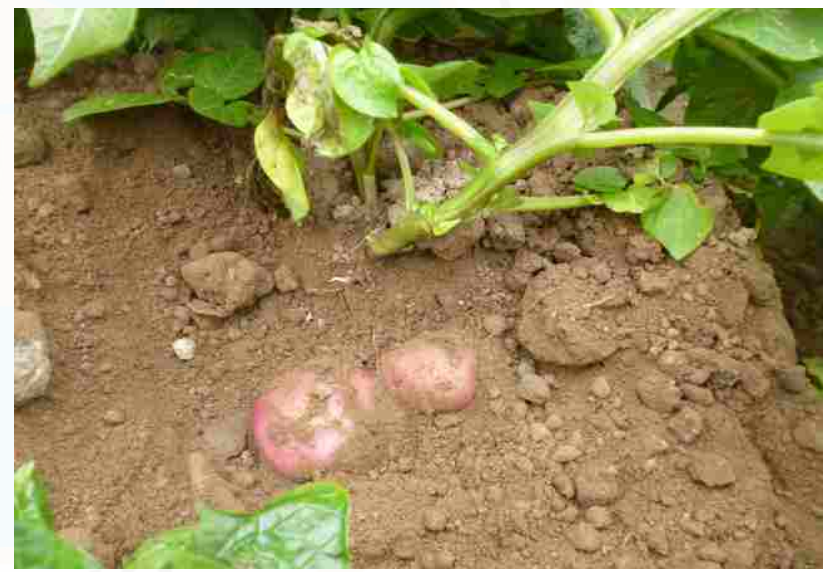

Figura 2. Tuberización en cv. Faustina.

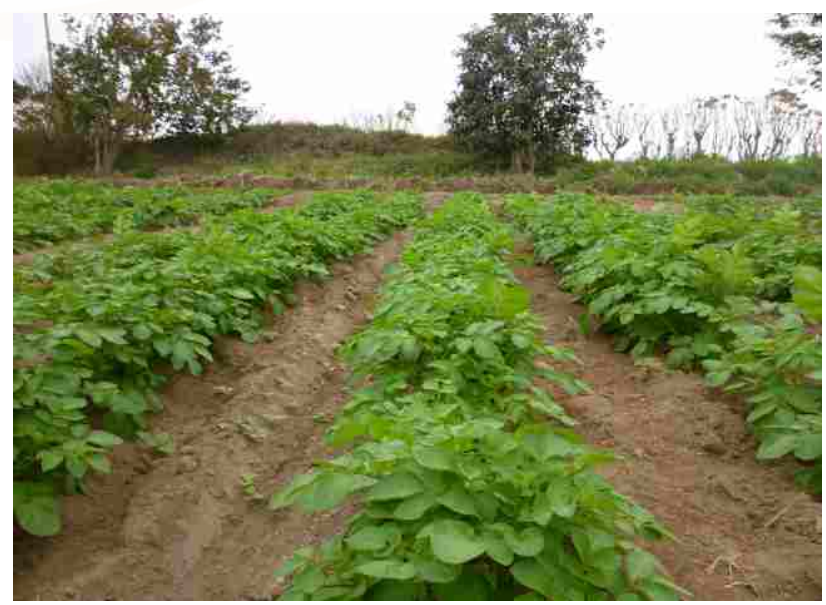

Figura 4. Clon Yasmine, de uniforme crecimiento vegetativo, tolerancia al calor y alta productividad. 